\title{
PAPER
}

\section{Chimpanzees and bonobos exhibit divergent spatial memory development}

\author{
Alexandra G. Rosati and Brian Hare
}

\begin{abstract}
Spatial cognition and memory are critical cognitive skills underlying foraging behaviors for all primates. While the emergence of these skills has been the focus of much research on human children, little is known about ontogenetic patterns shaping spatial cognition in other species. Comparative developmental studies of nonhuman apes can illuminate which aspects of human spatial development are shared with other primates, versus which aspects are unique to our lineage. Here we present three studies examining spatial memory development in our closest living relatives, chimpanzees (Pan troglodytes) and bonobos (P. paniscus). We first compared memory in a naturalistic foraging task where apes had to recall the location of resources hidden in a large outdoor enclosure with a variety of landmarks (Studies 1 and 2). We then compared older apes using a matched memory choice paradigm (Study 3). We found that chimpanzees exhibited more accurate spatial memory than bonobos across contexts, supporting predictions from these species' different feeding ecologies. Furthermore, chimpanzees - but not bonobos - showed developmental improvements in spatial memory, indicating that bonobos exhibit cognitive paedomorphism (delays in developmental timing) in their spatial abilities relative to chimpanzees. Together, these results indicate that the development of spatial memory may differ even between closely related species. Moreover, changes in the spatial domain can emerge during nonhuman ape ontogeny, much like some changes seen in human children.
\end{abstract}

\section{Research highlights}

- Developmental comparisons of nonhuman apes can provide insights into unique aspects of human ontogeny, and role of these processes in the emergence of different cognitive abilities.

- We compared spatial memory development in a large sample of semi-free-ranging chimpanzees (Pan troglodytes) and bonobos (P. paniscus), our closest phylogenetic relatives.

- Chimpanzees showed more accurate spatial memory than bonobos across contexts, supporting hypotheses from their different wild feeding ecologies.

- Chimpanzees, but not bonobos, showed age-related improvements in spatial memory, indicating that some developmental shifts in spatial cognition can also occur across the infant and juvenile period of nonhuman apes.

\section{Introduction}

Primates in the wild face complex spatial problems when foraging: they must recall the location of resources, determine the best navigation route between resources, and reorient when approaching locations from new perspectives (Janson \& Byrne, 2007; Normand \& Boesch,
2009). While much research has examined the emergence of these abilities in humans, little is known about whether nonhuman apes show similar developmental trajectories in their spatial abilities. Most comparative developmental studies to date take the approach of either contrasting human children with older or adult animals (Herrmann, Call, Hernadez-Lloreda, Hare \& Tomasello, 2007) or examining longitudinal development in a few individuals from a single species (Matsuzawa, Tomonaga \& Tanaka, 2006; Tomasello \& Carpenter, 2005). In terms of spatial cognition and memory specifically, few studies have examined age-related changes in the skills of other apes (but see Herrmann, Hare, Call \& Tomasello, 2010; Martin-Ordas, Haun, Colmenares \& Call, 2010). Importantly, theories from psychology suggest that developmental shifts in spatial cognition allow humans to solve spatial problems with a degree of flexibility and accuracy not seen in other species (e.g. Hermer-Vazquez, Moffet \& Munkholm, 2001; Hermer-Vazquez, Spelke \& Katnelson, 1999). These types of claims are fundamentally evolutionary in nature: if a given developmental pattern (and the mature level of competency that developmental process enables) is unique to humans, then that pattern should be found in our species alone. Consequently, comparative developmental studies that contrast ontogenetic patterns across species can illuminate what aspects of human development are unique to our lineage. 
Here we use this approach to examine the development of spatial memory skills in chimpanzees (Pan troglodytes) and bonobos ( $P$. paniscus $)$ - our closest extant phylogenetic relatives.

What aspects of spatial cognitive development might be unique to humans? Most notably, language is thought to underpin major ontogenetic shifts in how humans encode, integrate, and remember spatial information. For example, reorientation tasks with children and adults indicate that the acquisition of spatial language plays a causal role in allowing humans to rapidly form novel representations of space that combine geometric and feature information (Hermer \& Spelke, 1994; HermerVazquez et al., 2001; Hermer-Vazquez et al., 1999; Pyers, Shusterman, Senghas, Spelke \& Emmoret, 2010). Language may also bias the strategies that people spontaneously use to encode spatial frame of reference (Haun, Rapold, Call, Janzen \& Levinson, 2006b; Levinson, Kita, Haun \& Rasch, 2002), although it does not necessarily alter the set of strategies that individuals are capable of using (Li \& Gleitman, 2002). Finally, the emergence of place-based searching when locating hidden targets is correlated with the acquisition of spatial prepositions in the second year of life (Balcomb, Newcombe \& Ferrara, 2011). Collectively, these results indicate that language may be important in shaping spatial cognition across diverse contexts. However, they also illustrate the importance of differentiating whether language is necessary for certain ontogenetic changes to occur, facilitates the emergence of some skills without being strictly necessary, shows correlated development with particular skills without playing a causal role, or shapes what strategies humans prefer to use without changing their skills. Studies of comparative development in apes can be an important tool in differentiating these possibilities, as apes are our closest phylogenetic relatives, and share an extended juvenile period, but lack language (Matsuzawa, 2007). That is, apes are the best model for understanding what cognitive abilities and developmental patterns are uniquely human.

Do apes exhibit any human-like changes in the spatial domain? Models of development suggest that language acquisition and spatial development can be relatively independent in some contexts (Newcombe \& Huttenlocher, 2005). That is, some developmental shifts may be driven by intrinsic changes in spatial cognition, such as how sources of spatial information are weighted and combined across contexts (Learmonth, Nadel \& Newcombe, 2002; Learmonth, Newcombe, Sheridan \& Jones, 2008; Ratliff \& Newcombe, 2008). These types of models suggest that at least some human-like developmental patterns may be shared with nonhuman apes. In line with these ideas, increasing evidence indicates that apes do have sophisticated spatial abilities. For example, apes use cognitive maps of space to follow an optional search path when locating targets in large spaces (Menzel, SavageRumbaugh \& Menzel, 2002; Menzel, 1973), and these spatial memories may persist over long time scales
(Mendes \& Call, 2008). Chimpanzees can also use smallscale models to infer the location of hidden targets in a large-scale space, suggesting that some basic form of 'map-reading' does not require spatial language (Kuhlmeier \& Boysen, 2002). Finally, apes can solve some spatial problems using complex 'episodic-like' memory skills (Martin-Ordas et al., 2010). However, humans and apes also exhibit important differences. Apes are more dependent on spatial information than feature information, a pattern that matches that seen in younger children (Haun, Call, Janzeon, \& Levinson, 2006a), although they do use feature information in other contexts (Kanngiesser \& Call, 2010). In addition, apes show a preference for using an allocentric strategy when reasoning about spatial relations, again like the pattern seen in younger children prior to language-specific changes in preferred strategies (Haun et al., 2006b).

However, current comparative data on spatial cognition in apes are lacking in two regards for addressing claims about unique aspects of human spatial development. First, there are few data bearing on whether apes show any age-related changes in spatial memory and cognition. While previous studies do suggest improvement with age in some memory tasks (Martin-Ordas et al., 2010; Herrmann, Hare, Call \& Tomasello, 2010), providing support for the claims that some human-like patterns of development in the spatial domain may be shared with other apes, these tests do not include infants. Moreover, studies of infants have been limited to small samples of chimpanzees alone (Matsuzawa, 2007; Matsuzawa et al., 2006). Second, even though humans are equally related to both chimpanzees and bonobos, who diverged from each other less than 1 million years ago (Won \& Hey, 2005), there are few studies comparing the spatial abilities of these two species. Importantly, differences in the feeding ecology of bonobos and chimpanzees suggest that these species face different challenges while foraging (Kano, 1992; Malenky \& Wrangham, 1993; White, 1998; White \& Wrangham, 1988), so it is likely that they possess different abilities for dealing with spatial problems (e.g. Herrmann et al., 2010). In terms of understanding cognitive development, recent evidence further suggests that bonobos exhibit paedomorphism, or developmental delays in acquisition of traits, relative to chimpanzees. Paedomorphism broadly refers to changes in rate or timing of developmental events resulting in a juvenilized or underdeveloped set of adult traits (Lieberman, Carlo, de Leon \& Zollikofer, 2007). In terms of the development of cognition and behavior, bonobos exhibit large developmental delays in the acquisition of mature social skills, sometimes never reaching the same level of adult performance as chimpanzees (Wobber, Wrangham \& Hare, 2010). Consequently, a strong phylogenetic test of spatial cognitive development must involve both species to make inferences about developmental patterns that evolved in humans after our lineage split from Pan.

In the current set of studies, we therefore examined the development of spatial memory skills of chimpanzees 
and bonobos. In Studies 1 and 2, we utilized a naturalistic foraging context to assess how infant and juvenile apes use their spatial memory in a large, complex environment. Success in this task required place memory for hiding locations (Balcomb et al., 2011; Newcombe, Huttenlocher, Drummey \& Wiley, 1998) and recall of multiple items' locations over an extended temporal period (Sluzenski, Newcombe \& Satlow, 2004). Importantly, human children begin to recall locations and appropriately search for hidden targets only after acquiring spatial prepositions (Balcomb et al., 2011). Thus, our study can assess whether language is strictly necessary for the emergence of this human-like pattern. In study 3, we used a memory choice task to assess whether any differences persisted in an older sample of apes. Based on data from the feeding ecology and developmental patterns in these species, we hypothesized that chimpanzees would show more accurate spatial memory than bonobos due to their increased reliance on patchily distributed foods in the wild. In addition, we predicted that bonobos would exhibit developmental delays in the emergence of mature spatial cognition relative to chimpanzees, due to paedomorphism in their developmental trajectories.

\section{Study 1: Memory in a naturalistic foraging context}

Apes observed a human experimenter hiding 10 pieces of food in a large outdoor enclosure (test pieces). After a 20 min delay, they could enter the enclosure to search. We compared their success at locating the test pieces relative to a set of 10 pieces that were hidden when the ape was out of sight (control pieces). If apes recalled the hiding events they had previously observed, they should retrieve more test pieces than control pieces when searching.

\section{Methods}

Subjects

We tested 64 semi-free-ranging apes: 42 chimpanzees from Tchimpounga Chimpanzee Sanctuary in Pointe Noire, Republic of Congo, and 22 bonobos from Lola ya Bonobo Sanctuary in Kinshasa, Democratic Republic of Congo (see Table 1 for subject details). The chimpanzees ranged in age range from 2 to 11 years (mean age $M=6.5$ years; 22 females and 20 males) and the bonobos ranged in age from 2 to 12 years (mean age 6.6 years; nine females and 13 males). The majority of apes at the sanctuaries are wild-born orphans of the bushmeat and pet trade who came to the sanctuary at an early age. Upon arrival the apes are raised by a human surrogate parent in a peer nursery group, and then integrated into conspecific mixed-age groups. Previous research suggests that due to the high standard of care at sanctuaries, these apes are
Table 1 Subject information. Subjects of both species ( $C$ = chimpanzees, $B=$ bonobos) who completed Studies 1 (foraging task), 2 (foraging task with shorter delay), and 3 (memory choice)

\begin{tabular}{|c|c|c|c|c|}
\hline Subject & Species & Sex & Age & Studies \\
\hline Agnagui & $\mathrm{C}$ & $\mathrm{F}$ & 8 & 1 \\
\hline Bailiele & $\mathrm{C}$ & $\mathrm{M}$ & 4 & 1,2 \\
\hline Bayokele & $\mathrm{C}$ & $\mathrm{F}$ & 9 & 3 \\
\hline Betou & $\mathrm{C}$ & M & 3 & 1 \\
\hline Binda & $\mathrm{C}$ & $\mathrm{F}$ & 8 & 3 \\
\hline Blake & $\mathrm{C}$ & M & 8 & 3 \\
\hline Chimpie & $\mathrm{C}$ & $\mathrm{M}$ & 12 & 3 \\
\hline Dzeke & $\mathrm{C}$ & $\mathrm{M}$ & 8 & 1 \\
\hline Fanitouek & $\mathrm{C}$ & $\mathrm{F}$ & 11 & 3 \\
\hline Golfi & $\mathrm{C}$ & $\mathrm{F}$ & 8 & 1 \\
\hline Isabelle & $\mathrm{C}$ & $\mathrm{F}$ & 5 & 1 \\
\hline Kaoka & $\mathrm{C}$ & $\mathrm{M}$ & 4 & 1,2 \\
\hline Kimba & $\mathrm{C}$ & $\mathrm{M}$ & 2 & 1,2 \\
\hline Kimenga & $\mathrm{C}$ & M & 7 & 1 \\
\hline Kola & $\mathrm{C}$ & $\mathrm{M}$ & 13 & 3 \\
\hline Kouilou & $\mathrm{C}$ & $\mathrm{M}$ & 3 & 1,2 \\
\hline Koukele & $\mathrm{C}$ & $\mathrm{F}$ & 11 & 1 \\
\hline Koyamba & $\mathrm{C}$ & $\mathrm{M}$ & 7 & 1 \\
\hline Kudia & $\mathrm{C}$ & $\mathrm{F}$ & 5 & 1 \\
\hline Kuisa & $\mathrm{C}$ & $\mathrm{F}$ & 5 & 1 \\
\hline Kuzanza & $\mathrm{C}$ & $\mathrm{M}$ & 7 & 1 \\
\hline Lemba & $\mathrm{C}$ & $\mathrm{F}$ & 2 & 1,2 \\
\hline Likabou & $\mathrm{C}$ & $\mathrm{F}$ & 9 & 1 \\
\hline Loufoua & $\mathrm{C}$ & $\mathrm{M}$ & 9 & 1 \\
\hline Louise & $\mathrm{C}$ & $\mathrm{F}$ & 6 & 1 \\
\hline Luc & $\mathrm{C}$ & $\mathrm{M}$ & 7 & 1 \\
\hline Lufumbu & $\mathrm{C}$ & $\mathrm{M}$ & 8 & 1 \\
\hline Lusingou & $\mathrm{C}$ & M & 5 & 1,2 \\
\hline M'Bifini & $\mathrm{C}$ & $\mathrm{F}$ & 10 & 1 \\
\hline M'Vouti & $\mathrm{C}$ & $\mathrm{F}$ & 8 & 1 \\
\hline Mambou & $\mathrm{C}$ & $\mathrm{M}$ & 2 & 1,2 \\
\hline Manisa & $\mathrm{C}$ & $\mathrm{F}$ & 4 & 1,2 \\
\hline Mandzi & $\mathrm{C}$ & $\mathrm{M}$ & 7 & 1 \\
\hline Marcelle & $\mathrm{C}$ & $\mathrm{F}$ & 8 & 1 \\
\hline Moundele & $\mathrm{C}$ & $\mathrm{M}$ & 3 & 1,2 \\
\hline N'Gao & $\mathrm{C}$ & $\mathrm{M}$ & 8 & 1 \\
\hline N'Goro & $\mathrm{C}$ & $\mathrm{F}$ & 5 & 1 \\
\hline Nzanbi & $\mathrm{C}$ & $\mathrm{F}$ & 8 & 1 \\
\hline Pema & $\mathrm{C}$ & $\mathrm{F}$ & 8 & 1 \\
\hline Podive & $\mathrm{C}$ & $\mathrm{M}$ & 5 & 1 \\
\hline Pongou & $\mathrm{C}$ & $\mathrm{F}$ & 4 & 1 \\
\hline Shanga & $\mathrm{C}$ & $\mathrm{M}$ & 4 & 1,2 \\
\hline Silaho & $\mathrm{C}$ & $\mathrm{F}$ & 12 & 3 \\
\hline Sobele & $\mathrm{C}$ & $\mathrm{M}$ & 12 & 3 \\
\hline Tabonga & $\mathrm{C}$ & M & 11 & 3 \\
\hline Tambikiissa & $\mathrm{C}$ & $\mathrm{F}$ & 6 & 1 \\
\hline Tavich & $\mathrm{C}$ & $\mathrm{M}$ & 11 & 3 \\
\hline Tchivgna & $\mathrm{C}$ & $\mathrm{F}$ & 6 & 1 \\
\hline Tchimaka & $\mathrm{C}$ & $\mathrm{M}$ & 11 & 3 \\
\hline Tiki & $\mathrm{C}$ & $\mathrm{M}$ & 8 & 3 \\
\hline Timi & $\mathrm{C}$ & $\mathrm{M}$ & 12 & 3 \\
\hline Ulengue & $\mathrm{C}$ & M & 6 & 1 \\
\hline Vitika & $\mathrm{C}$ & $\mathrm{F}$ & 10 & 3 \\
\hline Wounda & $\mathrm{C}$ & $\mathrm{F}$ & 8 & 1 \\
\hline Zanaga & $\mathrm{C}$ & $\mathrm{F}$ & 10 & 1 \\
\hline Zimbana & $\mathrm{C}$ & $\mathrm{F}$ & 5 & 1 \\
\hline Api & B & $\mathrm{M}$ & 10 & 1,2 \\
\hline Bili & B & $\mathrm{M}$ & 9 & 2,3 \\
\hline Bisengo & B & $\mathrm{M}$ & 5 & 2 \\
\hline Boende & B & $\mathrm{M}$ & 9 & 2,3 \\
\hline Eleke & B & $\mathrm{M}$ & 5 & 2 \\
\hline Dilolo & B & $\mathrm{M}$ & 9 & 1,3 \\
\hline Fizi & B & M & 10 & 3 \\
\hline Ilebo & B & M & 8 & 2,3 \\
\hline Kalina & B & $\mathrm{F}$ & 12 & 3 \\
\hline Kananga & B & $\mathrm{F}$ & 2 & 1,2 \\
\hline Kasongo & B & M & 8 & $1,2,3$ \\
\hline Katako & B & $\mathrm{F}$ & 6 & 1,2 \\
\hline Kikongo & B & M & 9 & $1,2,3$ \\
\hline
\end{tabular}


Table 1 Continued

\begin{tabular}{lllll}
\hline Subject & Species & Sex & Age & Studies \\
\hline Kikwit & B & M & 12 & 3 \\
Kinshasa & B & F & 5 & 2 \\
Kipolo & B & M & 5 & 1,2 \\
Kisantu & B & F & 11 & 3 \\
Kodoro & B & M & 3 & 1,2 \\
Likasi & B & F & 9 & 1,2 \\
Lisala & B & F & 9 & 3 \\
Lomako & B & M & 3 & 1,2 \\
Lomami & B & M & 11 & 2 \\
Lukuru & B & F & 4 & 1,2 \\
Luozi & B & M & 7 & 1,2 \\
Mbandaka & B & M & 8 & 2 \\
Mabali & B & M & 7 & $1,2,3$ \\
Maniema & B & M & 8 & 1,3 \\
Masisi & B & F & 4 & 1,2 \\
Moyi & B & M & 3 & 2 \\
Muanda & B & F & 6 & 1,2 \\
Nioki & B & F & 11 & $1,2,3$ \\
Sake & B & F & 5 & 2 \\
Sandoa & B & F & 3 & 1,2 \\
Sankuru & B & F & 8 & 2 \\
Shibombo & B & M & 3 & 1,2 \\
Tchilenge & B & F & 7 & 1,2 \\
Tembo & B & M & 12 & 1 \\
Waka & B & F & 4 & 1,2 \\
Yolo & B & M & 7 & 2 \\
\hline
\end{tabular}

psychological healthy relative to other captive populations (Wobber \& Hare, 2011). All apes were socially housed, and received several feedings of fruits and vegetables every day. Apes had ad libitum access to water, and were not food restricted for testing. In addition, all apes were naïve to experimental studies involving hidden food in their enclosures. As exact birth dates for sanctuary apes are generally unknown, we used age estimates made by sanctuary veterinarians at arrival (typically when the infants are between 1 and 3 years old), and adjusted these age estimates using measurements of weight and patterns of dental emergence according to known patterns of ape development (following the methods described in Wobber et al., 2010), a technique that is further validated using the known ages of individuals born in the sanctuaries.

\section{Procedure}

Apes were tested individually in one session. In the demonstration phase, the ape watched as an experimenter entered an adjacent outdoor enclosure. Older apes watched from a building or tunnel that they commonly used to access the enclosure, whereas younger apes were held by their surrogate parent in the equivalent location in their enclosures. The experimenter hid 10 test pieces of food next to various landmarks in the enclosure. For each test piece, the experimenter first approached the ape's location (standing approximately $0.5 \mathrm{~m}$ away) and showed them a red bowl full of a highly preferred food (large slices of apple for bonobos; large pieces of banana for chimpanzees). The experimenter then held one piece of food in their hand and walked in a direct path to the hiding location while calling the ape's name and visibly waving the food piece. Once the experimenter reached the hiding location she called the ape's name until the ape oriented in her direction, and then hid the food on the ground while the ape watched. To control for any possible differences in motivation to search in the enclosure, as well as any potential cues to the food's location (such as smell), an additional 10 control pieces of the same food type had been previously hidden while the ape was in a different room and could not see the enclosure. Both test and control pieces were hidden under grass in the enclosure, so they were not visible unless the ape actively searched in that location. After a 20 min delay following the hiding of the last test piece, the ape was released into the enclosure for a 20 min search phase in which they could locate the food. For younger apes still being cared for in a nursery group, the surrogate human parent sat in the enclosure while they searched so they would not become nervous. The human parent never provided any cues the apes could use to locate the food.

Each ape completed only one session so we could examine their spontaneous ability to recall the location of the hidden food, without prior expectation that they would be tested. Apes were tested individually in a familiar enclosure: chimpanzees were tested in one of four enclosures corresponding to their social group, and bonobos were tested in two. As the enclosures were not identical in size across groups, food was hidden in a space approximately $30 \times 30 \mathrm{~m}$ adjacent to the ape's starting position in the demonstration phase. All food was hidden immediately adjacent to landmarks that were familiar and normally present in their enclosure. Landmarks included both natural items (such as trees, rocks, bushes, or grass patches) and artificial items (fence posts, water spouts, pools, and climbing structures). For each enclosure, there were two sets of 10 hiding locations that were approximately matched for location type (e.g. near a tree versus a rock) and distance to the ape's starting position. To ensure that certain locations were not intrinsically more attractive to the apes, the assignment of those sets as test or control was counterbalanced across subjects tested in the same enclosure. Finally, the order in which the experimenter hid the food at different locations was randomized. As a check for food motivation, any apes that failed to find any food in the search phase were given food in a post-test to confirm they were motivated to consume food; all apes readily ate food in this context.

\section{Data scoring and analysis}

All sessions were videotaped. After each session the experimenter entered the enclosure and checked the 20 hiding locations to confirm which pieces the ape had located. The order in which they were found and latency to find each piece was then coded from videotape. A second coder blind to the correct locations coded 20\% of sessions for reliability [pieces found: Cohen's kappa $=0.92$, latency to find pieces: Pearson's $r=0.99$, $<p<.001]$. To control for any potential differences in 


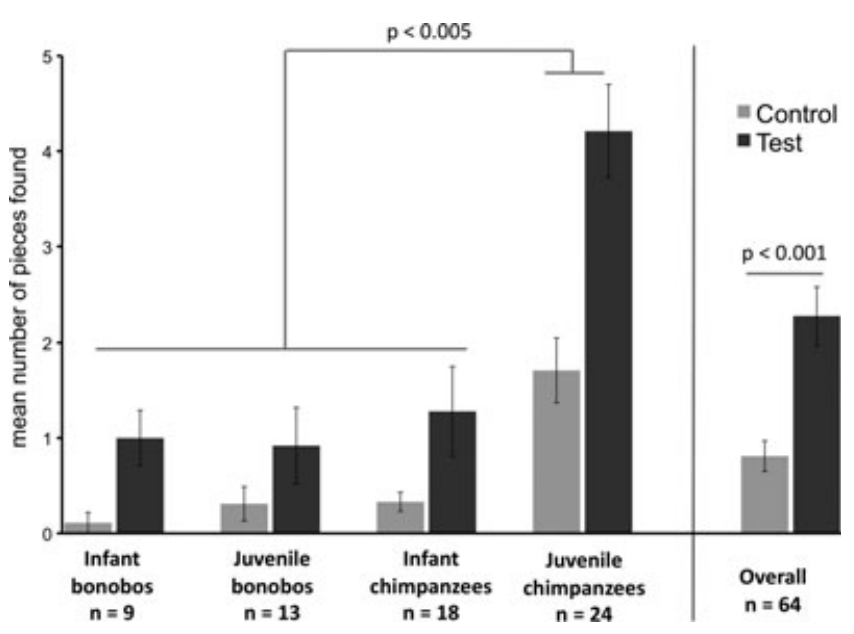

Figure 1 Performance in foraging task (Study 1). Chimpanzees searched in an enclosure for test pieces of food (that they had previously seen hidden) and control pieces (which they had not). Infants are age 2-5 years, and juveniles are age 612 years. Error bars represent standard error.

speed of search and eating across individuals, the analyses reported here examine only up to the first 10 pieces total that apes located, as an individual with perfect memory should first target the 10 test pieces they saw hidden (even if they continue to search in the enclosure for any remaining time in the search phase).

\section{Results and discussion}

We first compared the total number of test and control pieces the apes located (see Figure 1, and Table 2 for means). We split individuals into two age cohorts (infants: age 2-5 years; juveniles: age 6-12) based on patterns of aging in these species (Hamada, Udono, Teramoto \& Sugawara, 1996). A repeated-measures ANOVA with type (test or control piece) as a withinsubjects factor and species and age cohort as betweensubjects factors revealed main effects of type $[F(1$, $60)=27.86, \quad p<.001], \quad$ species $[F(1,60)=13.30$, $p=.001]$, and cohort $[F(1,60)=9.69, p<.005]$. These results show that (1) apes found more test than control pieces overall, indicating that they used their memory to search in the enclosure, (2) chimpanzees located more pieces than bonobos, and (3) older apes located more pieces than younger apes. In addition, there were two significant interactions. First, there was a significant interaction between species and cohort $[F(1,60)=8.65$, $p<.005]$; post-hoc tests revealed that older chimpanzees found more pieces than younger chimpanzees and bonobos overall [Tukey test, $p<.001$ for all significant cases]. This suggests that the overall cohort effect was largely driven by the performance of chimpanzees. Second, there was a significant interaction between species and type $[F(1,60)=4.28, p<.05]$; post hoc analyses indicated that chimpanzees found significantly more test pieces than did bonobos [Tukey tests, $p<.001$ for all significant cases]. Finally, there was a strong trend for a three-way interaction between species, cohort, and type $[F(1,60)=3.81, p=.056]$; post-hoc tests revealed that the older chimpanzees found significantly more test pieces than control pieces, and the number of test pieces they located exceeded the number of pieces of any type found by all other groups [Tukey test, $p<.001$ for all significant cases]. This suggests that the interaction between species and type was largely due to the performance of older chimpanzees, who located more test pieces relative to younger chimpanzees and bonobos overall.

We next examined the temporal order and timing of the apes' search patterns. Of the apes that located at least one piece of food (regardless of type) in the search phase, a significant number of both species located test pieces first [binomial tests; $28 / 32$ chimpanzees first found test pieces, $p<.001 ; 11 / 13$ bonobos found test pieces, $p<.05]$. Importantly, this result indicates that both chimpanzees and bonobos used their memory to select targeted test pieces when they entered the enclosure. When we collapsed species to increase statistical power, we found that apes also targeted test pieces on the second and third locations they searched [second piece: $29 / 34$ test, $p<.001$; third piece: $21 / 27$ test, $p<.01$ ]. It was not until the forth locations that apes did not locate significantly more test pieces $[13 / 19$ found test pieces, $p=.17$, $n s]$. Finally, we examined the latency for apes to locate their first test piece. Chimpanzees took an average of $186 \pm 53$ s to locate their first test piece, whereas bonobos took an average of $133 \pm 40 \mathrm{~s}$. A univariate GLM examining the latency for apes to locate their first test piece ( $n=42$ apes located at least one) indicated no effect of either species $[F(1,38)=0.50, p=.48, n s]$ or cohort $[F(1,39)=0.21, p=.65, n s]$, with no significant interactions. That is, both species, regardless of age, located their first test piece at similar speeds. This suggests that the species and age groups may have differed mainly in the number of locations they recalled (not the speed at which they acquired food); the ability to recall multiple locations first begins to emerge in human children during the second year of life (Sluzenski et al., 2004).

It is possible that chimpanzees found more pieces than bonobos because they were more active overall in search-

Table 2 Performance in Study 1. Average number of test and control pieces located by each species (up to the first 10 total found), overall and split into age cohorts

\begin{tabular}{lll}
\hline Age cohort & Bonobos & Chimpanzees \\
\hline Infants 2-5 years & $N=9$ Test: $1.00 \pm 0.29$ Control: $0.11 \pm 0.11$ & $N=18$ Test: $1.28 \pm 0.47$ Control: $0.33 \pm 0.16$ \\
Juveniles 6-12 years & $N=13$ Test: $0.92 \pm 0.40$ Control: $0.31 \pm 0.18$ & $N=24$ Test: $4.21 \pm 0.49$ Control: $1.71 \pm 0.34$ \\
Overall & $N=22$ Test: $0.95 \pm 0.26$ Control: $0.23 \pm 0.11$ & $N=42$ Test: $2.95 \pm 0.41$ Control: $1.12 \pm 0.23$ \\
\hline
\end{tabular}


ing for food in the enclosure, as opposed to because they exhibited more accurate memory. We thus conducted an analysis that assessed the accuracy with which individuals found test pieces over control pieces, reflecting their ability to recall the locations where they had seen food hidden previously. Specifically, we calculated a difference score (test pieces minus control pieces found) for each individual, again focusing on up to the first 10 pieces they located. With this analysis, an ape that located many pieces overall but did not specifically target test pieces would therefore receive a low accuracy score, much like an individual who located nothing. We first used an ANCOVA with species as a between-subjects factor and age as covariate to assess whether chimpanzees outperformed bonobos with the difference score when partialling out the effects of age. This revealed a main effect of species $[F(1,61)=5.88$, $p<.05]$ as well as age $[F(1,61)=4.17, p<.05]$. That is, chimpanzees outperformed bonobos even when controlling for any potential species differences in motivation to search, as well as any variation associated with age. We finally examined developmental patterns in each species alone using the difference score (see Figures $2 \mathrm{a}$ and $2 \mathrm{~b}$ ). In chimpanzees, there was a positive relationship between an individual's age and the difference score [linear regression, $\left.r^{2}=0.21, p<.005\right]$, whereas in bonobos there was not $\left[r^{2}=0.06, p=.26, n s\right]$. Together, these results indicate that chimpanzees exhibited more accurate spatial memory than bonobos, supporting predictions from their wild feeding ecology. Moreover, chimpanzees showed significant developmental improvements in the task, while bonobos continue to exhibit infant-like memory into puberty, supporting claims for bonobo paedomorphism.

\section{Study 2: Does reducing memory demands improve performance?}

In Study 1 we confirmed that subjects who failed to locate food were motivated to eat, by providing them with food after the test and checking if they ate it. In addition, our difference score analysis controlled for any potential differences in motivation to search in the enclosure. However, it is possible that some of the differences in performance seen in Study 1 may be due to differences in food motivation or general ability to forage, not memoryspecific deficits. To assess this possibility, in the second study we examined whether a sample of poorly performing bonobos and chimpanzees could succeed at the task when memory demands were reduced. In addition, we assessed whether a larger sample of bonobos showed agerelated improvements on this easier version of the task.

\section{Methods}

\section{Subjects}

We retested 10 younger chimpanzees (age range: 25 years, mean: 3.3 years) and 16 bonobos across the
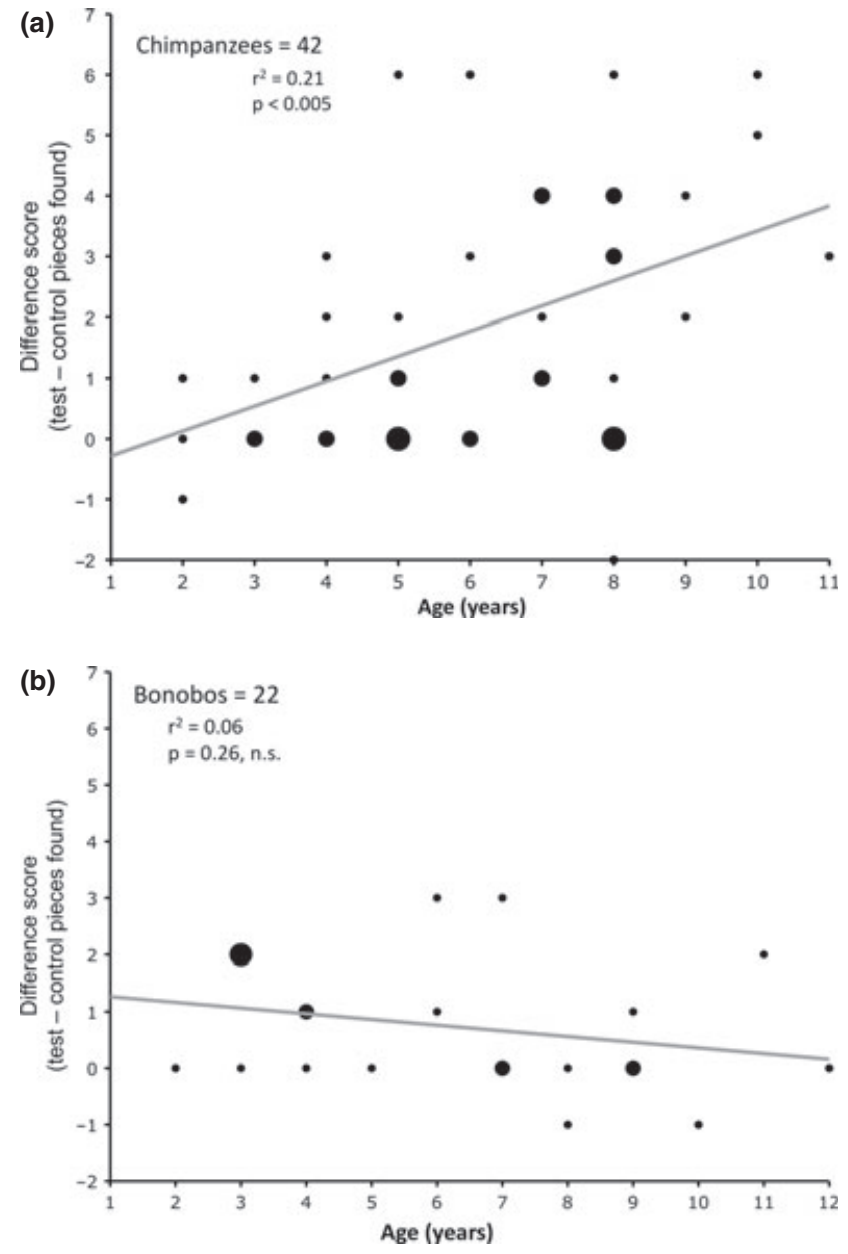

Figure 2 Correlation of difference score with age (Study 1). The difference score (test pieces - control pieces found) indexed the specificity of spatial searches while controlling for differences in motivation. Relationship between difference score and age in (a) chimpanzees and (b) bonobos. Dot size indicates frequency of individuals with that score.

studied age range (age range: $2-10$ years; mean: 5.4 years) that had all found two or fewer test pieces in Study 1. We also tested an additional 15 bonobos (age range: $3-11$ years, mean: 7.2 years) to assess whether bonobos showed developmental improvements in this easier task.

\section{Procedure}

We used methods similar to those in Study 1, but decreased the task's difficulty by (1) hiding only 4 test pieces in the demonstration phase and (2) releasing the apes to search immediately after the demonstration phase ended. Apes then had $5 \mathrm{~min}$ in the search phase to locate the food. As such, Study 2 imposed similar motivational and attentional demands on the apes (as they had to be motivated to search for food in the enclosure, as well as attend to the experimenter as she hid the food), but reduced the memory-specific demands of the task.

As this sample had generally not located control pieces in Study 1, we did not include the controls in the current 
study (the poorly performing subset of subjects found an average of $0.19 \pm 0.08$ control pieces over the entire 20 min search phase). Food was hidden in a space approximately $15 \times 20 \mathrm{~m}$ adjacent to the apes' observation position in the demonstration phase. We used the same six enclosures used in Study 1, plus an additional bonobo enclosure that was too small for use in Study 1, thus allowing us to expand our bonobo sample size for this study. Apes that had previously participated in Study 1 were tested on a different day for Study 2. To avoid learning effects with apes that participated in Study 1, we used four locations from their previous control set of locations (where they had not previously seen the experimenter hide food), selecting a subset of more proximal locations near the ape's observation location. For naive bonobos, food locations were also counterbalanced between two possible location sets in the in which enclosure they were tested. The was no difference in the performance of naïve bonobos and those who had participated in Study 1 [Mann-Whitney $=87.0, z=1.15$, $p=.25, n s]$, suggesting that the previous experience did not influence apes' performance here.

\section{Data analysis and scoring}

Data scoring was identical to that used in Study 1. Reliability from videotape was excellent [pieces found: Cohen's kappa $=1.0$, latency: $r=0.99<p<.001]$. We used non-parametric statistics to analyze the number of pieces found, as many apes did not locate any pieces, and parametric statistics to analyze latencies as before.

\section{Results and discussion}

We first examined whether individuals who had performed poorly in Study 1 showed improved performance on this easier task (see Figure 3a). We compared the number of test pieces found in the first 5 min of Study 1 with the number located in Study 2 (to equate the available search time in the two studies). The chimpanzees found an average of $0.50 \pm 0.27$ test pieces in Study 1, but here found $1.50 \pm 0.43$ pieces [Wilcoxon signed-rank test: $z=-2.06, n=10, \mathrm{~T}=5,5$ ties, $p<.05]$. The bonobos found an average of $0.50 \pm 0.16$ pieces in Study 1, but here found $1.31 \pm 0.27$ [Wilcoxon: $z=-2.59, n=16$, $\mathrm{T}=8,8$ ties, $z=2.59, p=.01]$. Thus, both species were able to locate more food when task difficulty was reduced. Finally, we compared the latency to find the first piece for those individuals that located at least one test piece in both studies $(n=12)$. Whereas these apes took an average of $214 \pm 72 \mathrm{~s}$ to locate their first piece in Study 1, they took only $49 \pm 22 \mathrm{~s}$ in Study 2 [paired samples $t$-test: $t(11)=2.28, p<.05]$. Thus, apes also retrieved food more quickly in this study. Together, this suggests that the poor performance of bonobos and young chimpanzees in Study 1 was due to the complex memory demands of the task, not a more general lack of motivation to search for food or inability to forage in the enclosure.

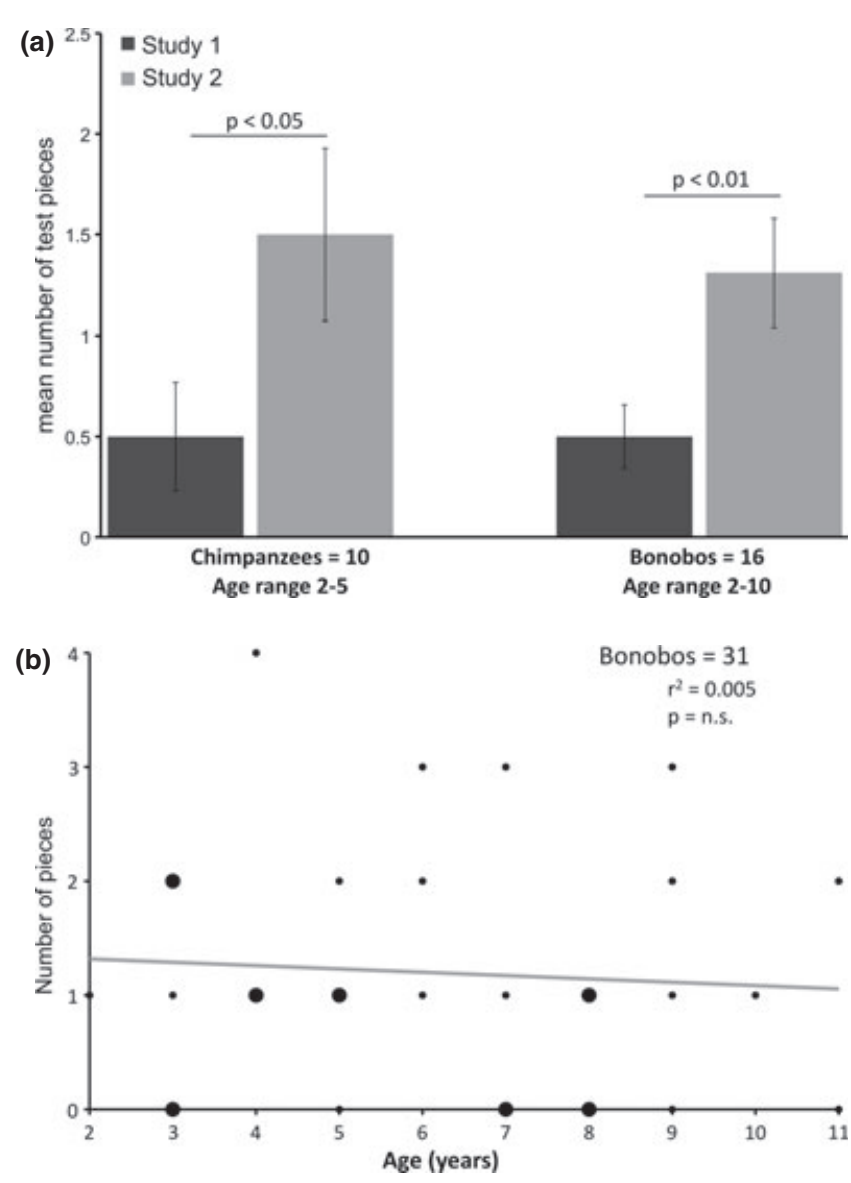

Figure 3 Reduced memory demands (Study 2). (a) Individuals who had found two or fewer test pieces in Study 1 were retested on a version of the task with reduced memory demands. Error bars represent standard error. (b) Relationship between number of pieces found and age in a larger sample of bonobos.

Second, we examined whether the larger sample of bonobos showed any age-related improvements in this easier task (see Figure $3 b)$. Infants $(n=13)$ found an average of $1.23 \pm 0.30$ pieces, and juveniles $(n=18)$ found $1.17 \pm 0.26$ pieces; a comparison of age cohorts revealed no difference [Mann-Whitney $=112.5$, $z=-0.19, p=.85, n s]$. The number of pieces found also did not correlate with age [Spearman's rho $=-0.07$, $p=.73, n s]$. Examining only those bonobos who located at least one piece $(n=22)$ revealed no difference in latency to locate that piece between age cohorts [infants: $71 \pm 27 \mathrm{~s}$ to locate their first piece; juveniles: $36 \pm 13 \mathrm{~s}$; $t(20)=1.21, p=.24, n s]$. Thus, there was no evidence for developmental improvements in bonobo spatial memory, even when the task demands were reduced.

\section{Study 3: Memory choice task}

The results from Studies 1 and 2 suggest that chimpanzees and bonobos differ in their spatial memory abilities. However, as the two species are cared for at different sanctuaries, they were tested with different outdoor 
enclosures. In Study 3, we therefore examined sub-adult apes on a memory choice task that was exactly matched for both species, thus controlling for any potential differences between enclosures used in Studies 1 and 2 . Specifically, apes had to recall the location of a preferred food hidden under one of four cups for a delay of 1 minute; the other three cups contained a non-preferred food. To assess whether apes exhibited improved memory in certain contexts, we further manipulated two factors that modulate memory in humans: emotional salience (LaBar \& Cabeza, 2006) and reward motivation (Shohamy \& Adcock, 2010), but for the purposes of the present manuscript we focus on comparison of the species' memory abilities.

\section{Methods \\ Subjects}

We tested 14 chimpanzees (five females and nine males; mean age $=10.4$ years; age range $8-13$ ) and 14 bonobos (four females and 10 males; mean age $=9.4$ years; age range 7-12) from the same sanctuary populations. Six of the bonobos also participated in Studies 1 or 2 (see Table 1). None of these apes of either species had participated in delayed memory choice tasks, but the majority of them had participated in a variety of studies requiring them to recall the location of food over shorter intervals (e.g. object permanence or spatial rotation; Herrmann et al., 2010).

\section{Pretest procedure}

All subjects first completed an introductory session consisting of a food preference test and a memory pretest. In the food preference pretest, apes completed 12 food preference trials to confirm preferences across (1) a larger piece of a preferred food type; (2) a smaller piece of the preferred food type; and (3) a non-preferred food type (in chimpanzees: preferred food was banana, non-preferred food was cucumber; bonobos: preferred food was apple, non-preferred food was lettuce). Apes completed four trials for each possible pairing of the three outcomes, with side assignment counterbalanced across trials. In preference trials, apes chose the large preferred food on $95.1 \pm 1.6 \%$ of trials in which it was available, the small preferred food on $54.0 \pm 2.0 \%$ of trials, and the nonpreferred food on $1.8 \pm 1.1 \%$ of trials, with no differences between the two species [t-tests; $p>.05$ in all cases]. This indicates that we selected food options of high, medium, and low value that the two species preferred at similar rates.

The memory pretest used the same basic paradigm as in the main task described below, but involved only a $10 \mathrm{~s}$ memory delay. To meet criteria, the ape had to select the location with the target (preferred) food on five of the previous six trials. If they failed to do so, they completed another round of six trials, with up to 24 trials in a given day. Results indicated that the two species did not differ in the number of pretest rounds they needed to reach criteria [chimpanzees: $2.0 \pm 0.43$ rounds; bonobos $1.71 \pm 0.26 ; t(26)=0.56, p=.58, n s]$ nor in the total number of pretest trials where they chose correctly [chimpanzees: $\quad 78.0 \pm 3.4 \% \quad$ correct; bonobos: $80.0 \pm 2.6 \% ; t(26)=0.26, p=.80, n s]$. Thus, both species were equally capable of recalling the preferred food's location following a short delay in this paradigm.

\section{Test procedure}

In all test sessions, apes sat across from the experimenter at a table ( $80 \mathrm{~cm}$ wide, $40 \mathrm{~cm}$ deep, $50 \mathrm{~cm}$ high) with a sliding top, separated by wire mesh or bars. In trials, the experimenter placed four identical overturned cups $(9 \mathrm{~cm}$ diameter, $13.5 \mathrm{~cm}$ tall) in a row along the front of the table. The experimenter first held up the target preferred food in the ape's view, and then placed that food in front of the relevant cup. Next she placed pieces of non-preferred food in front of the other cups, from left to right, and waited 3 s so apes could view the locations of the different foods. Next she covered all pieces with their respective cup from left to right. Finally, she placed a large occluder (44 cm high, middle sections $62 \mathrm{~cm}$ wide; folding wings $31 \mathrm{~cm}$ wide) at the front of the table such that the apes could no longer see the table top during the delay. After 1 minute, she removed the occluder and pushed the table forward to allow the ape to choose one of the cups. Once the ape chose by pointing at or touching their choice, the experimenter uncovered the hidden food and gave it to the ape. There was a $20 \mathrm{~s}$ inter-trial interval (ITI) between trials, starting when the ape received their chosen food item. On each trial, the ape had $20 \mathrm{~s}$ to choose; if they failed to do so the trial was repeated at the end of the session. The location of the target preferred food was counterbalanced within a session across the four possible locations and quasirandomized (with no more than two trials in a row with the same location assignment).

Apes completed two test sessions (on separate days), each with 12 trials. In the reward session, we manipulated the value of the target reward, comparing trials where the target food was either the large piece of preferred food (six reward trials) or the smaller piece (six neutral trials). In the emotion session, we manipulated the emotional salience of the target reward by comparing trials where the experimenter produced an emotional, attentiongetting vocalization while looking at the target food (six emotion trials) to trials with no vocalization (six neutral trials); the target food here was always the smaller piece of the preferred food. In each session, the trial type (neutral versus manipulation) was quasi-randomized (with no more than three trials in a row of the same type). For the emotion trials, the experimenter's vocalization was modeled after a chimpanzee waa-bark (van Hooff, 1973); both species have responded to humans 
producing this vocalization in previous studies (Hare \& Tomasello, 2004; Itakura, Agnetta, Hare \& Tomasello, 1999; MacLean \& Hare, 2012). The experimenter produced this vocalization during the $3 \mathrm{~s}$ viewing period after placing all the food on the table, but prior to covering the food items with cups. When producing the waa-bark, the experimenter gazed at the location of the preferred target food.

\section{Data scoring and analysis}

The location that apes chose was coded live by the experimenter. For reliability, $20 \%$ of trials were coded from videotape by a second coder who was blind to the correct location. Agreement between the two coders was perfect $($ Cohen's kappa $=1.00)$. Proportion data were arcsine square-root transformed to normalize the data.

\section{Results and discussion}

We first examined how successful the apes were at recalling the location of the preferred food in the test sessions. Overall, chimpanzees selected the correct cup on $51.5 \pm 3.1 \%$ of trials, significantly above chance of $25 \%$ [one-sample $t$-test, $t(13)=8.61, p<.001$ ] . Bonobos selected the correct location on $38.7 \pm 2.3 \%$ of trials, also above chance $[t(13)=5.88, p<.001]$. Thus, both species were successful at recalling the location of the preferred food. We next conducted an ANCOVA partialling out any potential effects of age. While there was no effect of age in this sub-adult sample $[F(1,25)=0.21$, $p=.65, n s]$, there was a main effect of species $[F(1$, $25)=10.56, p<.005]$, indicating that chimpanzees selected the target location more often than bonobos (see Figure 4).

Second, we examined the pattern of errors of the two species. For all trials where the ape chose incorrectly, we assessed whether the location they selected was adjacent to the preferred food's true location. On incorrect trials, chimpanzees selected an adjacent location on $71.1 \pm 2.9 \%$ of trials, whereas bonobos only selected an adjacent location on $57.8 \pm 3.3 \%$ of trials, a significant difference $[t(26)=2.72, p<.05]$. This pattern of errors suggests that chimpanzees retained more spatial information than bonobos even when they chose incorrectly. Together, these results indicate that chimpanzees demonstrated more accurate spatial memory than bonobos, suggesting that the developmental differences we identified in Study 1 hold on a matched task, and also likely persist into adulthood given the older age of apes this study.

Finally, we examined how our reward and emotion manipulations influenced the two species' performance. As the neutral trials were procedurally identical in both sessions, and there was no difference in the apes' performance in neutral trials across the two sessions $[t(27)=1.02, p=.32, n s]$, we averaged each individual's performance across neutral trials for all further analyses

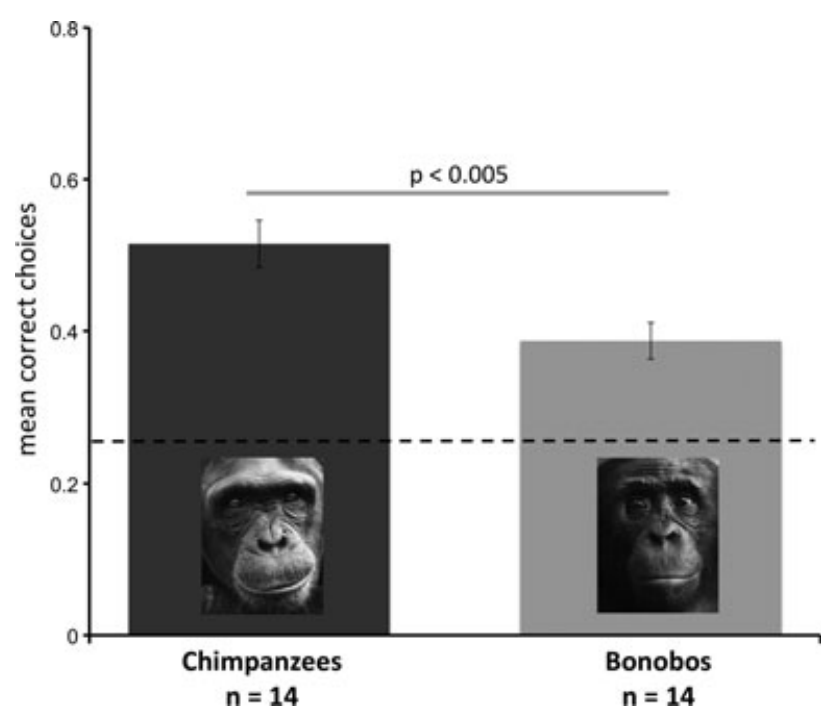

Figure 4 Memory choice task (Study 3). Chimpanzees and bonobos were presented with a memory task where the target preferred food was hidden under one of four cups. Chance is $25 \%$, indicated by dashed bar. Error bars represent standard error.

to reduce the number of factors. That is, we compared performance across three trial types: neutral, reward, and emotion trials. Overall, apes chose the correct cup on $39.6 \pm 2.6 \%$ of neutral trials, on $47.6 \pm 3.9 \%$ of emotion trials, and on $53.6 \pm 4.2 \%$ of reward trials. A repeated-measures ANOVA with trial type as a within-subjects factor and species as a between-subjects factor revealed a main effect of species $[F(1$, 26) $=14.21, p=.001]$, with chimpanzees outperforming bonobos. In addition, there was a main effect of trial type $[F(2,52)=3.57, p<.05]$; post-hoc tests indicated that apes performed significantly better on reward trials compared to neutral trials [Tukey test, $p<.05$ ]. There were no interactions between species and trial type. Thus, this analysis again confirmed that chimpanzees exhibited more accurate memory than bonobos, but also indicates that both species recalled the preferred food's location more when the target was a high-value reward than a low-value reward. This suggests that reward systems may modulate memory in apes much like the patterns seen in humans (Adcock, Thangavel, Whitfield-Gabrieli, Knutson \& Gabrieli, 2006), including in spatial contexts (Murty, LaBar, Hamilton \& Adcock, 2011). However, our emotion manipulation did not influence the apes' memory. There are several possible explanations for this result. First, our emotion manipulation was different from typical studies of emotional memory in humans in that the stimulus itself was not emotionally significant; rather the experimenter directed an emotional vocalization towards the food's location. Second, this situation (producing a waa-bark towards food) may have been unusual for the apes, as apes typically do not produce such vocalizations in feeding contexts (van Hooff, 1973). Finally, the apes 
may not have perceived the human-made vocalization as particularly salient in this context.

\section{General discussion}

These comparative results examining the development of spatial memory in Pan provide evidence for three major conclusions. First, chimpanzees have more accurate spatial memory than bonobos: they were more successful in the naturalistic foraging task (Study 1), and the results from the memory choice task (Study 3) revealed that these differences persisted into adulthood. Second, our results indicate the importance of using a comparative developmental approach to understanding the differences in cognitive abilities across species, as even closely related chimpanzees and bonobos showed very different developmental trajectories in spatial memory. In particular, while these species showed spatial memory abilities that were similar in infancy, older chimpanzees showed significant improvements, whereas bonobos did not (Study 1). There was also no evidence of age-related improvement in bonobos in a foraging task with reduced memory demands (Study 2). Finally, the developmental results from chimpanzees (Study 1) suggest that some ontogenetic shifts in spatial cognition occur in other apes. Together, these results indicate that studies integrating comparative and developmental approaches can illuminate the origins of cognitive traits across species, including humans.

Why might chimpanzees and bonobos exhibit different spatial memory skills? Ultimately, species differences in spatial memory appear to reflect differences in wild feeding ecology in many taxa. For example, birds that cache more food in the wild have more accurate memory (Balda \& Kamil, 1988) and larger brain regions supporting memory (Krebs, Sherry, Healy, Perry \& Vaccarino, 1989). Similar findings from voles (Jacobs, Gaulin, Sherry \& Hoffman, 1990) and callitrichids also lend support to the relationship between ecology and memory skills. Thus, one possibility is that chimpanzees and bonobos also exhibit different spatial memory skills due to differences in their feeding ecology. Indeed, wild chimpanzees depend more on patchily distributed fruit, whereas bonobos depend more on homogeneously distributed resources such as terrestrial herbaceous vegetation (Malenky \& Wrangham, 1993), suggesting that chimpanzees many need more sophisticated memory abilities to locate their patchy food resources. More broadly, chimpanzees and bonobos exhibit a suite of ecological differences: chimpanzees depend on more seasonably variable food sources, face more competition for less-abundant food, engage in more risky hunting behaviors, and use tools for extractive foraging - a behavior virtually absent in wild bonobos (Gilby \& Wrangham, 2007; McGrew, 1998; White, 1998; White \& Wrangham, 1988). Increasing evidence suggests that these wild ecological differences align with experimental data on cognitive abilities in these species. For example, chimpanzees exhibit lower inter-individual tolerance in social contexts (Hare, Melis, Woods, Hastings \& Wrangham, 2007; Wobber et al., 2010), more skillfulness at solving extractive foraging problems (Herrmann et al., 2010), and a greater willingness to accept decision-making 'costs' such as risk or temporal delays (Haun, Nawroth \& Call, 2011; Heilbronner, Rosati, Hare \& Hauser, 2008). Together with the current results, this provides support for the hypothesis that feeding ecology has been an important factor shaping the cognition and behavior of these species (Kano, 1992; Wrangham \& Peterson, 1996).

Our results also suggest a developmental explanation for the observed overall differences in spatial memory: chimpanzees exhibited significant improvements in spatial memory between infancy and adolescence, whereas bonobos retained infant-like spatial memory skills as they aged. These results generally support the claim that heterochrony (Gould, 1977), or differences in developmental timing, is the evolutionary mechanism underlying some differences in chimpanzee and bonobo traits. In particular, the paedomorphism hypothesis predicts that bonobos should retain more juvenile-like traits into adulthood relative to chimpanzees (Hare, Wobber \& Wrangam, 2012; Wobber et al., 2010). Previous support for this claim comes from comparative studies of these species' morphology indicating that bonobos have a more juvenilized skull form and size, with decoupled relationships between cranial shape and size in adults relative to chimpanzees (Lieberman et al., 2007; Shea, 1983, 1984, 1989) (but see Mitteroecker, Gunz \& Bookstein, 2005). Previous evidence also indicates developmental delays in behavioral characteristics such as aggression, play, and inter-individual tolerance (Furuichi \& Ihobe, 1994; Hohmann \& Fruth, 1993; Kuroda, 1989; Palagi, 2006; Wobber et al., 2010) and social-cognitive skills (Wobber et al., 2010). Importantly, chimpanzees and bonobos often show different developmental trajectories for the same suite of behavioral and cognitive traits thought to be related to foraging. For example, aggression and inter-individual tolerance are indicators of the different levels of feeding competition seen in these species, and social-cognitive tasks examining response inhibition and reversal learning are likely tapping skills needed to forage effectively in a social group. The spatial memory skills explored here are a critical component of wild foraging abilities (Janson \& Byrne, 2007). Thus, changes in developmental timing may be an important evolutionary mechanism for generating this interconnected suite of behaviorial differences across the two species.

Finally, our results indicate that apes exhibit some ontogenetic changes in spatial cognition: chimpanzees exhibited improvements in place-based memory, in particular in their ability to accurately recall multiple target locations. Notably, in human children, improvements in place memory are associated with acquisition of spatial prepositions (Balcomb et al., 2011). Our results, however, suggest that these types of ontogenetic shifts in place- 
based searching may potentially be due to intrinsic changes in spatial abilities. For example, this result may be due to maturational changes in the brain regions supporting spatial cognition. Human life history is notable for its extended juvenile period, with a longer duration of brain development and cognitive plasticity (Bjorklund \& Green, 1992; Kaplan, Hill, Lancaster \& Hurtado, 2000). Studies of brain maturation in humans further suggest that several brain regions supporting spatial cognition - including the hippocampus and its surrounding medial temporal lobe (MTL), the parietal cortex, and the basal ganglia (Burgess, 2008) - show significant reorganization over childhood and adolescence (Giedd, Blumenthal, Jeffries, Castellnos, Liu, Zijdenbos, Paus, Evans \& Rapoport, 1999; Lenroot \& Giedd, 2006; Utsunomiya, Takano, Okazaki \& Mitsudome, 1999). Importantly, nonhuman apes also have extended juvenile periods with postnatal brain development: humans and apes share extended growth rate patterns relative to other primates (Leigh, 2004), as well as exhibiting distinct phases in brain growth (Rice, 2002). Thus, many of the same maturational changes in regions supporting spatial cognition in humans may also be important in restructuring the brains of nonhuman apes.

However, our results certainly do not suggest that language is not important for human spatial development. Even if some developmental changes can occur in the absence of language in other species, language may nonetheless be a causal factor in the types of change seen in humans. Rather, our results indicate that comparative developmental studies of apes may be one important tool for assessing the role that language may play in shaping different abilities across contexts. For example, whereas the types of place memory tasks focused on here are correlated with language acquisition (Balcomb et al., 2011), there is stronger evidence that the ability to reorient using integrated geometric and feature cues is causally dependent on language in both children and adults (Hermer \& Spelke, 1994; Hermer-Vazquez et al., 2001; Hermer-Vazquez et al., 1999; Lee \& Spelke, 2010; Pyers et al., 2010). Our results cannot address those specific claims, as we did not test apes' abilities while reorienting. Nonetheless, it is notable that most previous comparative research on this topic involved species that are distantly related to humans, including rodents, birds, and fish (Batty, BloomWeld, Spetch \& Sturdy, 2009; Cheng, 1986; Lee \& Spelke, 2010; Vargas, López, Salas \& Thinus-Blanc, 2004; Wang, Hermer \& Spelke, 1999) (but see Gouteux, Thinus-Blanc \& Vauclair, 2001, for evidence from rhesus macaques). Comparative developmental studies of apes may therefore be especially illuminating when attempting to understand the phylogenetic distribution of these types of abilities. Finally, it is currently unclear whether apes show any age-related changes in how they process spatial frames of reference, a context where language dictates the preferred strategies that humans exhibit (Haun et al., 2006b; Levinson et al., 2002). Future studies should therefore more specifically address whether developmental changes occur in how chimpanzees and bonobos solve these types of problems.

What do these results mean for claims about humanunique traits in the spatial domain? First, although chimpanzees alone are most often utilized as a model for the last common ancestor of humans and nonhuman apes (Hare, 2007; Wrangham \& Pilbeam, 2001), the comparative developmental data reported here provide contrasting views of ancestral cognitive traits in the human linage. Even though chimpanzees and bonobos are very closely related, their developmental trajectories and mature levels of performance were quite different: the bonobos exhibited no developmental shifts in spatial cognition, whereas the evidence from chimpanzees indicates that some ontogenetic changes can emerge in nonhuman apes. Second, comparative studies of nonhuman apes may be important for elucidating the function of spatial cognitive traits in humans from an ultimate perspective (Matsuzawa, 2007). Chimpanzees and bonobos showed significant differences in their spatial memory, and these differences align with current data on their wild feeding ecologies. Interestingly, human feeding ecology also differs from that of other great apes in several important ways: human hunter-gatherers use far larger home ranges and daily ranging patterns than other apes, and exhibit a unique pattern of central place foraging where individuals return to a centralized location with food (Hill et al., 2009; Marlowe, 2005). This increased reliance on distant food sources, and novel pattern of central-place foraging, raises the possibility that humans possess derived cognitive traits to solve these more complex spatial problems. For future research to identify any such uniquely human traits, it is important to integrate comparative data on the ontogeny of both chimpanzees and bonobos. That is, studies of comparative development are critical to draw strong inferences about what traits are unique to our lineage.

\section{Acknowledgements}

We thank Kerri Rodriguez for assistance with coding, and Felix Warneken for comments on a previous version of the manuscript. At Tchimpounga Chimpanzee Sanctuary, we thank Rebeca Atencia, Debby Cox, Lisa Pharoh, Keith Brown, and Jane Goodall Institute USA in collaboration with the Congolese Ministere de la Recherche Scientifique et de l'Innovation Technique (research permit: 009/MRS/DGRST/DMAST) for hosting our research. We appreciate the assistance of the animal caretakers, especially Jean Maboto, Lydia Bibimbou, Bernard Moumbaka, Jean Aime Tchikaya, and Luc Bongo. At Lola ya Bonobo we thank Claudine Andre, Dominique Morel, Fanny Mehl, and Pierrot Mbonzo for their support in collaboration with the Ministry of Research and the Ministry of Environment in the Democratic Republic of Congo for supporting our research (research permit: \#MIN.RS/SG/004/2009). We 
appreciate the assistance of the animal caregivers, especially Jean Claude Nzumbi, Stany Mokando, and Philippe Kunaka. All behavioral tests had IACUC approval from Duke University and were in accordance with the laws where they were conducted. This work was supported in part by European Research Commission Advanced Grant Agreement 233297 and National Science Foundation grants NSF-BCS-08-27552-02 and NSF-BCS-10-25172 to BH and a L.S.B. Leakey Grant and Duke Sigma Xi Sally Hughes-Schrader Travel Grant to AR.

\section{References}

Adcock, R.A., Thangavel, A., Whitfield-Gabrieli, S., Knutson, B., \& Gabrieli, J.D.E. (2006). Reward-motivated learning: mesolimbic activation precedes memory formation. Neuron, 50, 507-517.

Balcomb, F., Newcombe, N.S., \& Ferrara, K. (2011). Finding where and saying where: developmental relationships between place learning and language in the second year. Journal of Cognition and Development, 12, 315-331.

Balda, R.P., \& Kamil, A.C. (1988). A comparative study of cache recovery by three corvid species. Animal Behaviour, 38, 486-495.

Batty, E.R., BloomWeld, L.L., Spetch, M.L., \& Sturdy, C.B. (2009). Comparing black-capped (Poecile atricapillus) and mountain chickadees (Poecile gambeli): use of geometric and featural information in a spatial orientation task. Animal Cognition, 12, 633-641.

Bjorklund, D., \& Green, B. (1992). The adaptive nature of cognitive immaturity. American Psychologist, 47, 46-54.

Burgess, N. (2008). Spatial cognition and the brain. Annals of the New York Academy of Sciences, 1124, 77-97.

Cheng, K. (1986). A purely geometric module in the rat's spatial representation. Cognition, 23, 149-178.

Furuichi, T., \& Ihobe, H. (1994). Variation in male relationships in bonobos and chimpanzees. Behaviour, 130, 211-228.

Giedd, J.N., Blumenthal, J., Jeffries, N.O., Castellnos, F.X., Liu, H., Zijdenbos, A., Paus, T., Evans, A.C., \& Rapoport, J.L. (1999). Brain development during childhood and adolescence: a longitudinal MRI study. Nature Neuroscience, 2, 861-862.

Gilby, I.C., \& Wrangham, R. (2007). Risk-prone hunting by chimpanzees (Pan troglodytes schweinfurthii) increases during periods of high diet quality. Behavioral Ecology and Sociobiology, 61, 1771-1779.

Gould, S. (1977). Ontogeny and phylogeny. Cambridge, MA: Harvard University Press.

Gouteux, S., Thinus-Blanc, C., \& Vauclair, J. (2001). Rhesus monkeys use geomtery and nongeometric information during a reorientation task. Journal of Experiemental Psychology: General, 130, 505-519.

Hamada, Y., Udono, T., Teramoto, M., \& Sugawara, T. (1996). The growth pattern of chimpanzees: somatic growth and reproductive maturation in Pan troglodytes. Primates, 37 , 279-295.

Hare, B. (2007). From nonhuman to human mind: what changed and why. Current Directions in Psychological Science, 16, 60-64.

Hare, B., Melis, A.P., Woods, V., Hastings, S., \& Wrangham, R. (2007). Tolerance allows bonobos to outperform chimpanzees on a cooperative task. Current Biology, 17, 619-623.
Hare, B., \& Tomasello, M. (2004). Chimpanzees are more skilful in competitive than in cooperative cognitive tasks. Animal Behaviour, 68, 571-581.

Hare, B., Wobber, V., \& Wrangam, R. (2012). The selfdomestication hypothesis: evolution of bonobo psychology is due to selection against aggression. Animal Behaviour, 83, 573 585 .

Haun, D.B.M., Call, J., Janzeon, G., \& Levinson, S.C. (2006a). Evolutionary psychology of spatial representations in the Hominidae. Current Biology, 16, 1736-1740.

Haun, D.B.M., Nawroth, C., \& Call, J. (2011). Great apes' risktaking strategies in a decision making task. PLoS One, 6, e28801.

Haun, D.B.M., Rapold, C.J., Call, J., Janzen, G., \& Levinson, S.C. (2006b). Cognitive cladistics and cultural override in Hominid spatial cognition. Proceedings of the National Academy of Sciences, USA, 103, 17568-17573.

Heilbronner, S.H., Rosati, A.G., Hare, B., \& Hauser, M.D. (2008). A fruit in the hand or two in the bush? Divergent risk preferences in chimpanzees and bonobos. Biology Letters, $\mathbf{4}$, 246-249.

Hermer, L., \& Spelke, E. (1994). A geometric process for spatial reorientation in young children. Nature, 370 $57-59$.

Hermer-Vazquez, L., Moffet, A., \& Munkholm, P. (2001). Language, space, and the development of cognitive flexibility in humans: the case of two spatial memory tasks. Cognition, 79, 263-299.

Hermer-Vazquez, L., Spelke, E., \& Katnelson, A.S. (1999). Sources of flexibility in human cognition: dual-task studies of space and language. Cognitive Psychology, 39, 3-36.

Herrmann, E., Call, J., Hernadez-Lloreda, M.V., Hare, B., \& Tomasello, M. (2007). Humans have evolved specialized skills of social cognition: the cultural intelligence hypothesis. Science, 317, 1360-1366.

Herrmann, E., Hare, B., Call, J., \& Tomasello, M. (2010). Differences in the cognitive skills of bonobos and chimpanzees. PLoS One, 5, e12438.

Hill, K., Barton, M., \& Hurtado, M. (2009). The emergence of human uniqueness: characters underlying behavioral modernity. Evolutionary Anthropology, 18, 187-200.

Hohmann, G., \& Fruth, B. (1993). Field observations on meat sharing among bonobos (Pan paniscus). Folia Primatologica, 60, 225-229.

Itakura, S., Agnetta, B., Hare, B., \& Tomasello, M. (1999). Chimpanzee use of human and conspecific social cues to locate hidden food. Developmental Science, 2, 448-456.

Jacobs, L.F., Gaulin, S.J.C., Sherry, D.F., \& Hoffman, G.E. (1990). Evolution of spatial cognition: sex-specific patterns of spatial behavior predict hippocampal size. Proceedings of the National Academy of Sciences, USA, 87, 6349-6352.

Janson, C.H., \& Byrne, R. (2007). What wild primates know about resources: opening up the black box. Animal Cognition, 10, 357-367.

Kanngiesser, P., \& Call, J. (2010). Bonobos, chimpanzees, gorillas, and orangutans use feature and spatial cues in two spatial memory tasks. Animal Cognition, 13, 419-430.

Kano, T. (1992). The last ape: Pygmy chimpanzee behavior and ecology. Stanford, CA: Stanford University Press.

Kaplan, H., Hill, K., Lancaster, J., \& Hurtado, M. (2000). A theory of human life history evolution: diet, intelligence, and longevity. Evolutionary Anthropology, 9, 156-185. 
Krebs, J.R., Sherry, D.F., Healy, S.D., Perry, H., \& Vaccarino, A.L. (1989). Hippocampal specialization of food-storing birds. Proceedings of the National Academy of Sciences, USA, 86, 1388-1392.

Kuhlmeier, V.A., \& Boysen, S.T. (2002). Chimpanzees' recognition of the spatial and object similarities between a scale model and its referent. Psychological Science, 13, 60-63.

Kuroda, S. (1989). Developmental retardation and behavioral characteristics of pygmy chimpanzees. In P. Heltne \& L. Marquardt (Eds.), Understanding chimpanzees (pp. 184193). Cambridge, MA: Harvard University Press.

LaBar, K.S., \& Cabeza, R. (2006). Cognitive neuroscience of emotional memory. Nature Reviews Neuroscience, 7, 54-64.

Learmonth, A.E., Nadel, L., \& Newcombe, N.S. (2002). Children's use of landmarks: implications for modularity theory. Psychological Science, 13, 337-341.

Learmonth, A.E., Newcombe, N.S., Sheridan, N., \& Jones, M. (2008). Why size counts: children's spatial reorientation in large and small enclosures. Developmental Science, 11, 414 426.

Lee, S.A., \& Spelke, E. (2010). Two systems of spatial representation underlying navigation. Experiemental Brain Research, 206, 179-188.

Leigh, S.R. (2004). Brain growth, life history, and cognition in primate and human evolution. American Journal of Primatology, 62, 139-164.

Lenroot, R.K., \& Giedd, J.N. (2006). Brain development in children and adolescents: insights from anatomical magnetic resonance imaging. Neuroscience and Biobehavioral Reviews, 30, 718-729.

Levinson, S.C., Kita, S., Haun, D.B.M., \& Rasch, B.H. (2002). Returning the tables: language affects spatial reasoning. Cognition, 84, 144-188.

Li, P., \& Gleitman, L. (2002). Turning the tables: language and spatial reasoning. Cognition, 83, 265-294.

Lieberman, D.A., Carlo, J., de Leon, M.P., \& Zollikofer, C.P.E. (2007). A geometric morphometric analysis of heterochrony in the cranium of chimpanzees and bonobos. Journal of Human Evolution, 52, 647-662.

McGrew, W.C. (1998). Culture in nonhuman primates? Annual Review of Anthropology, 27, 301-328.

MacLean, E.L., \& Hare, B. (2012). Bonobos and chimpanzees infer the target of another's attention. Animal Behaviour, 83, 345-353.

Malenky, R.K., \& Wrangham, R.W. (1993). A quantitative comparison of terrestrial herbaceous food consumption by Pan paniscus in the Lomako Forest, Zaire, and Pan troglodytes in the Kibale Forest, Uganda. American Journal of Primatology, 32, 1-12.

Marlowe, F.W. (2005). Hunter-gatherers and human evolution. Evolutionary Anthropology, 14, 54-67.

Martin-Ordas, G., Haun, D., Colmenares, F., \& Call, J. (2010). Keeping track of time: evidence for episodic-like memory in great apes. Animal Cognition, 13, 331-340. doi: 10.1007/ s10071-009-0282-4.

Matsuzawa, T. (2007). Comparative cognitive development. Developmental Science, 10, 97-103.

Matsuzawa, T., Tomonaga, M., \& Tanaka, M. (Eds.) (2006). Cognitive development in chimpanzees. Tokyo: Springer-Verlag.

Mendes, N., \& Call, J. (2008). Spatial memory in chimpanzees: single-trial learning, 24-hour, 3-month long term memory. Paper presented at the International Primatological Society Conference XXII Edinburgh, UK.
Menzel, C.R., Savage-Rumbaugh, E.S., \& Menzel, E.W. (2002). Bonobo (Pan paniscus) spatial memory and communication in a 20-hectare forest. International Journal of Primatology, 23, 601-619.

Menzel, E.W. (1973). Chimpanzee spatial memory organization. Science, 182, 943-945.

Mitteroecker, P., Gunz, P., \& Bookstein, F. (2005). Heterochrony and geometric morphometrics: a comparison of cranial growth in Pan paniscus versus Pan troglodytes. Evolution and Development, 7, 244-258.

Murty, V.P., LaBar, K.S., Hamilton, D.A., \& Adcock, R.A. (2011). Is all motivation good for learning? Dissociable influences of approach and avoidance motivation in declarative memory. Learning and Memory, 18, 712-717.

Newcombe, N.S., \& Huttenlocher, J. (2005). Development of spatial cognition. In D. Kuhn \& R.S. Siegler (Eds.), Handbook of child psychology (6th edn., pp. 734-776). Hobokem NJ: John Wiley and Sons.

Newcombe, N.S., Huttenlocher, J., Drummey, A., \& Wiley, J.G. (1998). The development of spatial location coding: place learning and dead reckoning in the second and third years. Cognitive Development, 13, 185-200.

Normand, E., \& Boesch, C. (2009). Sophisticated Euclidean maps in forest chimpanzees. Animal Behaviour, 77, 1195 1201.

Palagi, E. (2006). Social play in bonobos (Pan paniscus) and chimpanzees (Pan troglodytes): implications for natural social systems and interindividual relationships. American Journal of Physical Anthropology, 129, 418-436.

Pyers, J.E., Shusterman, A., Senghas, A., Spelke, E.S., \& Emmoret, K. (2010). Evidence from an emerging sign language reveals that language supports spatial cognition. Proceedings of the National Academy of Sciences, USA, 107, 12116-12120.

Ratliff, K.R., \& Newcombe, N.S. (2008). Reorienting when clues conflct: evidence for an adaptive-combination view. Psychological Science, 19, 1301-1307.

Rice, S.H. (2002). The role of heterochrony in primate brain evolution. in K.J.M.N. Minugh-Purvis (Ed.), Human evolution through developmental change (pp. 154-172). Baltimore, MD: Johns Hopkins University Press.

Rosati, A.G., Stevens, J.R., Hare, B., \& Hauser, M.D. (2007). The evolutionary origins of human patience: temporal preferences in chimpanzees, bonobos, and human adults. Current Biology, 17, 1663-1668.

Shea, B. (1983). Paedomorphosis and neoteny in the pygmy chimpanzee. Science, 222, 521-522.

Shea, B. (1984). An allometric perspective on the morphological and evolutionary relationships between pygmy (Pan paniscus) and common (Pan troglodytes) chimpanzees. In R.L. Susman (Ed.), The pygmy chimpanzee: Evolutionary biology and behavior (pp. 89-130). New York: Plenum Press.

Shea, B. (1989). Heterochrony in human evolution: the case for neoteny reconsidered. Yearbook of Physical Anthropology, 32, 69-104.

Shohamy, D., \& Adcock, R.A. (2010). Dopamine and adaptive memory. Trends in Cognitive Sciences, 14, 464472.

Sluzenski, J., Newcombe, N.S., \& Satlow, E. (2004). Knowing where things are in the second year of life: implications for hippocampal development. Journal of Cognitive Neuroscience, 16, 1443-1451. 
Tomasello, M., \& Carpenter, M. (2005). The emergence of social cognition in three young chimpanzees. Monographs of the Society for Research in Child Development, 70 (1, Serial No. 279).

Utsunomiya, H., Takano, K., Okazaki, M., \& Mitsudome, A. (1999). Development of the temporal lobe in infants and children: analysis by MR-based volumetry. American Journal of Neuroradiology, 20, 717-720.

van Hooff, J.A.R.A.M. (1973). A structural analysis of the social behavior of a semi-captive group of chimpanzees. European Monographs in Social Psychology, 4, 75-162.

Vargas, J.P., López, J.C., Salas, C., \& Thinus-Blanc, C. (2004). Encoding of geometric and featural spatial information by goldfish (Carassius auratus). Journal of Comparative Psychology, 118, 206-216.

Wang, R.F., Hermer, L., \& Spelke, E. (1999). Mechanisms of reorientation and object localization by children: a comparison with rats. Behavorial Neuroscience, 113, 475-485.

White, F.J. (1998). Seasonality and socioecology: the importance of variation in fruit abundance to bonobo sociality. International Journal of Primatology, 19, 1013-1027.
White, F.J., \& Wrangham, R.W. (1988). Feeding competition and patch size in the chimpanzee species Pan paniscus and Pan troglodytes. Behaviour, 105, 148-164.

Wobber, V., \& Hare, B. (2011). Psychological health of orphan bonobos and chimpanzees in African sanctuaries. PLoS One, 6, e17147.

Wobber, V., Wrangham, R., \& Hare, B. (2010). Bonobos exhibit delayed development of social behavior and cognition relative to chimpanzees. Current Biology, 20, 226-230.

Won, Y.J., \& Hey, J. (2005). Divergence population genetics of chimpanzees. Molecular Biology and Evolution, 22, 297-307.

Wrangham, R., \& Peterson, D. (1996). Demonic males: Apes and the origins of human violence. London: Bloomsbury.

Wrangham, R., \& Pilbeam, D. (2001). African apes as time machines. in B.M.F. Galdikas, N.E. Briggs, L.K. Sheeran, G.L. Shapiro \& J. Goodall (Eds.), All apes great and small. Volume I: African apes (pp. 5-18). New York: Kluwer Academic / Plenum Publishers.

Received: 20 September 2011

Accepted: 8 June 2012 